\title{
Effects of Atomic Oxygen and Grease on Outgassing and Adhesion of Silicone Elastomers for Space Applications
}

\author{
Henry C. de Groh III ${ }^{1}$, Bernadette J. Puleo, and Bruce M. Steinetz \\ NASA Glenn Research Center, Cleveland, Ohio, 44135 USA \\ E-mail: $\underline{\text { Henry.C.deGroh@nasa.gov }}$
}

\begin{abstract}
An investigation of silicone elastomers for seals used in docking and habitat systems for future space exploration vehicles is being conducted at NASA. For certain missions, NASA is considering androgynous docking systems where two vehicles each having a seal would be required to: dock for a period of time, seal effectively, and then separate with minimum push-off forces for undocking. Silicone materials are generally chosen for their wide operating temperatures and low leakage rates. However silicone materials are often sticky and usually exhibit considerable adhesion when mated against metals and silicone surfaces. This paper investigates the adhesion unit pressure for a space rated silicone material (S038370) for either seal-on-seal ( $\mathrm{SoS})$ or seal-on-aluminum ( $\mathrm{SoAl})$ operation modes in the following conditions: as-received, after ground-based atomic-oxygen (AO) pre-treatment, after application of a thin coating of a space-qualified grease (Braycote $601 \mathrm{EF}$ ), and after a combination of AO pre-treatment and grease coating. In order of descending adhesion reduction, the AO treatment reduced seal adhesion the most, followed by the AO plus grease pre-treatment, followed by the grease treatment. The effects of various treatments on silicone (S0383-70 and ELA-SA$401)$ outgassing properties were also investigated. The leading adhesion AO pretreatment reduction led to a slight decrease in outgassing for the S0383-70 material and virtually no change in ELA-SA-401 outgassing.
\end{abstract}

Key Words: silicone, rubber, elastomer, adhesion, outgas, CVCM, TML, seals.

\section{Introduction}

The National Aeronautics and Space Administration (NASA) is evaluating different silicone elastomers for seals for docking and habitat systems being considered for future missions $[1,2]$. In addition to exhibiting extremely low leakage, the seals must meet stringent low-outgassing requirements, operate over a broad temperature range, and exhibit low adhesion to minimize decoupling or separation forces. The primary class of elastomers that meet the wide operating temperature range for these applications are silicone-based rubbers [3]. However, these elastomers have inherent adhesive properties, which make them sticky, creating potential difficulties when trying to separate docked spacecraft or hatches $[4,5]$. Three different adhesion-lowering treatments have been considered: atomic oxygen (AO), grease coating, and an AO treatment combined with a grease coating. A heat treatment plus AO treatment was examined in an effort to lower outgassing.

${ }^{1}$ To whom all correspondence should be addressed. 
The AO pre-treatment developed by NASA Glenn has shown excellent results in reducing seal adhesion with moderate fluence levels $[4,6]$. Grease was considered in two approaches: first as a stand-alone treatment and second as an addition to the baseline AO pre-treatment method. Grease was investigated as a means to reduce adhesion for the following reasons: its effectiveness at lowering adhesion was unknown; the AO pre-treatment, though very effective, requires special equipment and a vacuum tank large enough to accommodate the seal diameter; and the special equipment costs make AO treatments expensive compared to grease. The effects of a light grease coating on adhesion and outgassing are presented here. Several different elastomer compounds have been considered and tested; this paper is limited to results from tests of the elastomer compounds S0383-70 supplied by Parker-Hannifin Corporation, and ELA-SA-401 supplied by Esterline Corporation.

Prior work has shown that atomic oxygen, characteristic of that present in Low-Earth-Orbit (LEO) combines with the silicone in silicone-based elastomers to form a very thin, glassy surface coating $[4,7]$. At moderate $\mathrm{AO}$ levels, this $\mathrm{SiO}_{\mathrm{x}^{-}}$ based coating does not significantly degrade the sealing properties of the rubber [6].

Space-qualified grease has been used in the past by NASA to lubricate gears and to ease the placement of elastomer seals $[8,9]$. Greases are also being considered as a way to lower unwanted seal adhesion. Braycote Micronic $601 \mathrm{EF}$, a space qualified perfluoroether grease, was examined in this study [10].

When elastomer seals are used in space, it is important for them to be stable, and have a low total mass loss (TML) and low collected volatile condensable materials $(\mathrm{CVCM})$. Current requirements are for TML $<1 \%$ and $\mathrm{CVCM}<0.1 \%$. However, there is always motivation for outgassing to be as low as possible to minimize contamination of sensitive surfaces such as windows and tracking systems. Thus tougher requirements are frequently proposed and may be imposed in some situations in the future.

The effects of $\mathrm{AO}$ and grease coatings on seal outgassing were unknown, thus a campaign was begun to determine the effects of these treatments on TML and CVCM. This paper reports the results of that campaign.

\section{Procedures}

\subsection{Specimens}

This study used cylindrical button specimens cut from sheets to measure adhesion, and \#2-106 o-rings to measure outgassing.

2.1.1 Buttons for Adhesion testing

Cylindrical $9.1 \mathrm{~mm}$ diameter buttons of S0383-70 elastomer were cut from $5.4 \mathrm{~mm}$ thick sheet material using a drill press and a custom-made core drill lubricated with soap, as described previously [6]. Buttons to be tested with grease were then weighed, and an amount of Braycote Micronic $601 \mathrm{EF}$ grease approximating $1.2 \mathrm{mg} / \mathrm{cm}^{2}$ applied to its mating surface. Small amounts of grease were then added or subtracted to achieve the desired rate of $1.2 \mathrm{mg} / \mathrm{cm}^{2}$. The adhesion buttons had an average rate of coverage of $1.17 \mathrm{mg} / \mathrm{cm}^{2}$ and a standard deviation of 
$0.11 \mathrm{mg} / \mathrm{cm}^{2}$. Only S0383-70 buttons were made; no adhesion tests on ELA-SA401 are reported in this paper.

2.1.2 O-rings for outgas testing

This study used S0383-70 and ELA-SA-401 o-rings of the size \#2-106 (inner diameter $=4.42 \mathrm{~mm}$ and cord width $=2.62 \mathrm{~mm}$ ) which were small enough to fit in the crucible used in outgas testing without being cut or sectioned in any way. It was believed that sectioning after AO treatment, and there-by exposing the sample's interior, could increase outgassing [6]. Sheet material was not used because the process by which the o-rings are made mimics better the docking seal manufacturing process.

2.2 Treatments

\subsubsection{Atomic Oxygen}

Elastomer S0383-70 button specimens to be tested with grease were AO exposed in an atomic oxygen facility, referred to as Tank 9 at the NASA Glenn Research Center (GRC) [6], to a fluence of $1.25 \times 10^{20}$ atoms $/ \mathrm{cm}^{2}$. Fluence levels in the facility were determined using Kapton witness specimens. O-rings for grease and outgas testing made of S0383-70 and ELA-SA-401 were AO exposed to $1.0 \times 10^{20}$ atoms $/ \mathrm{cm}^{2}$ using SPI Supplies Plasma Prep II atomic oxygen facilities at GRC [6]. O-rings were hung by a fine wire to insure AO exposure to all surfaces. Another set of o-rings were exposed to a fluence of $4.9 \times 10^{20}$ atoms $/ \mathrm{cm}^{2}$ after a 4 - day vacuum bake in a related effort to lower outgassing.

2.2.2 Heat Treatments

In an effort to lower TML and CVCM a treatment was used on S0383-70 and ELA-SA-401 o-rings which consisted of a 4-day bake under vacuum at a temperature of $205^{\circ} \mathrm{C}$, after which, the o-rings were exposed to an $\mathrm{AO}$ fluence of $4.9 \times 10^{20}$ atoms $/ \mathrm{cm}^{2}$.

2.2.3 Grease Coating

As-received buttons and \#2-106 o-rings to be greased were first wiped with $99 \%$ isopropyl alcohol, dried, and weighed. The procedure used to grease the buttons is mentioned in Section 2.1.1. The o-rings were covered with Braycote Micronic $601 \mathrm{EF}$ perfluoroether grease over their entire surface at an average rate of $1.19 \mathrm{mg} / \mathrm{cm}^{2}$ with a standard deviation among o-rings of $0.08 \mathrm{mg} / \mathrm{cm}^{2}$. The rate of coverage was measured by weighing the o-ring before and after grease application and the amount of grease adjusted until the desired coverage was achieved. To put this application rate into perspective the Sun Protection Factor (SPF) application rate for sunscreen on a person's skin is $2 \mathrm{mg} / \mathrm{cm}^{2}$.

2.3 Adhesion testing

Procedures used for adhesion testing are discussed in detail elsewhere [6]. Adhesion was measured between the flat surfaces of two buttons SoS and between a button and a flat, anodized aluminum alloy plate SoAl with the plate having an average roughness, $\mathrm{Ra}$, of $13 \mu$ in ( 0.33 micrometers). The aluminum alloy was 6061 T651 and the anodizing was MIL-A-8625 T II. Button specimens were brought together, compressed $25 \%$, and held for 72,000 seconds (20 hours). The load and unload rate was $0.01 \mathrm{in} . / \mathrm{s}(0.254 \mathrm{~mm} / \mathrm{s})$. Adhesion was measured during unloading using a force transducer. Specimens mated with other specimens with a 
similar grease coating were tested repeatedly. Once a grease coated button was mated with an uncoated specimen, such as an anodized aluminum plate, the greased button would not be tested again until its coating had been re-applied and measured. The anodized aluminum plate used in SoAl tests was cleaned with $99 \%$ Isopropyl alcohol before each test.

2.4 Outgas testing

All o-ring outgas test specimens were sent to Orange County Material Test Laboratories in Anaheim, California, who used ASTM Standard Designation: E 59593 [11] for TML and CVCM testing.

\section{Results}

\subsection{Adhesion}

Figure 1 shows the adhesion of the compound S0383-70 in the various sealing modes of interest, seal-on-seal SoS and seal-on-aluminum SoAl and with various treatments imposed on the rubber. This group of experiments was designed to determine if Braycote Micronic $601 \mathrm{EF}$ perfluoroether grease could be used to lower the adhesive characteristics of S0383-70. The bar data in Fig. 1 are the averages listed in Table 1. The lines in the bars of data represent the range of values from the tests performed and can also be found in Table 1. Figure 1 shows the asreceived adhesion and how effective an $\mathrm{AO}$ treatment of $1.25 \times 10^{20}$ atoms $/ \mathrm{cm}^{2}$ is, effectively lowering SoS and SoAl adhesion to 0.5 psi or essentially zero. The application of $1.2 \mathrm{mg} / \mathrm{cm}^{2}$ of grease to as-received S0383-70 also lowered adhesion in both SoS and SoAl arrangements. Application of the grease resulted in an approximately $70 \%$ decrease in adhesion compared to as-received levels. This level of adhesion reduction achieved with grease only may be of value in many applications. However, the goal for future docking systems is for the seal adhesion to be below 0.5 psi. The adhesion of AO treated S0383-70 increased with the application of the grease to about 5 psi for the SoS case, and 3 psi for SoAl. These conservative (worst case) values of 5 and 3 psi for the $\mathrm{AO}+$ grease tests are cited rather than the averages of 2.74 and 1.1 psi for SoS and SoAl, respectively because of the stochastic nature of adhesion and adhesion testing which is reflected by the standard deviations provided in Table 1. 


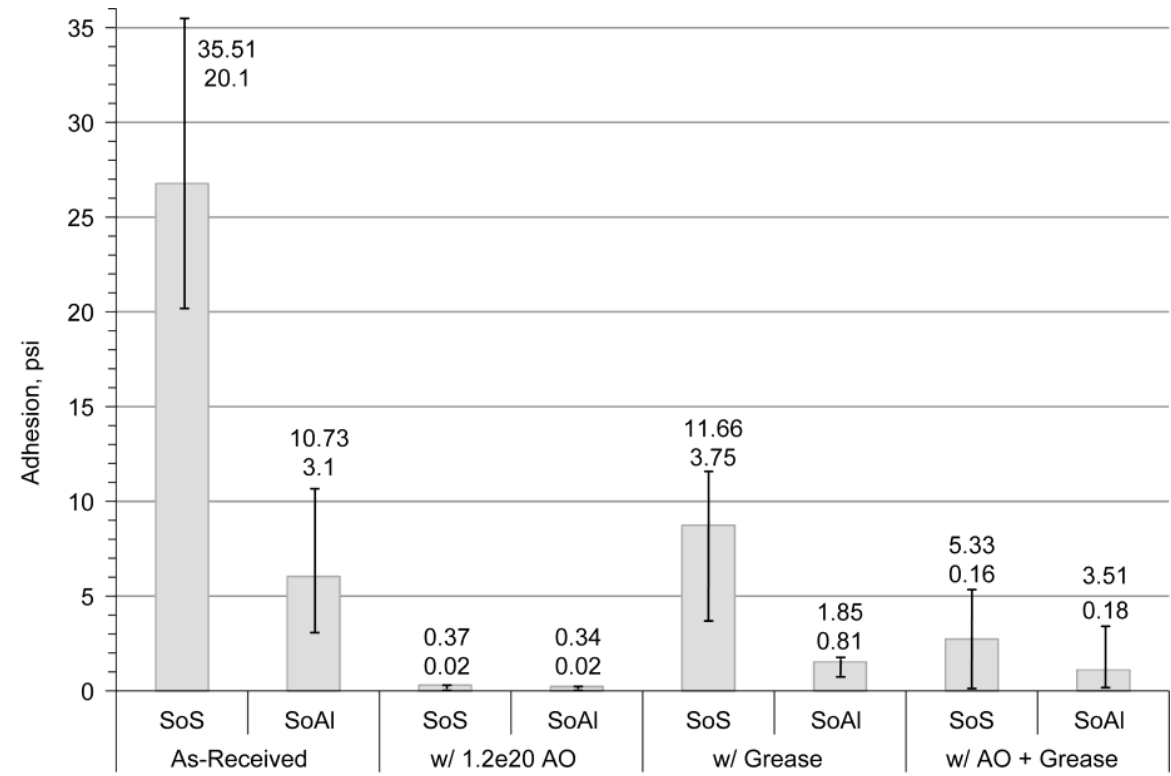

Fig.1 Adhesion in lb/in. ${ }^{2}$ of S0383-70 elastomer in Seal-on-Seal (SoS) and Sealon-aluminum (SoAl) test modes, in the following conditions: 1. As-received; 2. After receiving an atomic oxygen fluence of $1.25 \times 10^{20}$ atoms $/ \mathrm{cm}^{2} \mathrm{AO} ; 3$. After application of Braycote Micronic 601 perfluoroether grease at a rate of $1.2 \mathrm{mg} / \mathrm{cm}^{2} ; 4$. After $1.25 \times 10^{20}$ atoms $/ \mathrm{cm}^{2}$ AO plus $1.2 \mathrm{mg} / \mathrm{cm}^{2}$ Braycote Micronic 601 grease.

Table 1 Adhesion in lb/in. ${ }^{2}$ of S0383-70 elastomer in Seal-on-Seal and Seal-onAluminum test modes Conditions: As received, AO fluence of $1.25 \times 10^{20}$ atoms $/ \mathrm{cm}^{2}$, application of Braycote Micronic $601 \mathrm{EF}$ perfluoroether grease, and a combination of AO fluence of $1.25 \times 10^{20}$ atoms $/ \mathrm{cm}^{2}$ plus Braycote Micronic $601 \mathrm{EF}$ perfluoroether grease.

\begin{tabular}{|c|c|c|c|c|c|c|c|c|}
\cline { 2 - 9 } \multicolumn{1}{c|}{} & \multicolumn{2}{c|}{ As-received } & \multicolumn{2}{c|}{ w/AO } & \multicolumn{2}{c|}{ w/Grease } & \multicolumn{2}{c|}{ w/AO + Grease } \\
\hline Test \# & SoS & SoAl & SoS & SoAl & SoS & SoAl & SoS & SoAl \\
\hline 1 & 24.67 & 4.28 & 0.37 & 0.34 & 3.75 & 1.83 & 0.16 & 0.37 \\
\hline 2 & 20.1 & 10.73 & 0.02 & 0.02 & 10.83 & 1.85 & 5.23 & 0.18 \\
\hline 3 & 35.51 & 3.1 & - & - & 11.66 & 0.91 & 5.33 & 3.51 \\
\hline 4 & - & - & - & - & - & - & 0.23 & 0.32 \\
\hline Average & 26.76 & 6.04 & 0.20 & 0.18 & 8.75 & 1.53 & 2.74 & 1.10 \\
\hline $\begin{array}{l}\text { Standard } \\
\text { deviation }\end{array}$ & 6.46 & 3.35 & 0.18 & 0.16 & 3.55 & 0.44 & 2.54 & 1.40 \\
\hline
\end{tabular}




\subsection{Outgassing}

Outgas testing of as-received material and after the 4-day vacuum bake $+\mathrm{AO}$, AO only treatment, and grease coating, are shown below in Fig.2. All outgassing data are from uncut, \#2-106 o-rings. Per the ASTM standard each measurement was an average of 3 o-ring tests; one repeat measurement was made for the tests using grease and the two measurements then averaged.

The combined bake at $205{ }^{\circ} \mathrm{C}$ and $\mathrm{AO}$ treatment did not lower the outgassing of S0383-70 significantly compared to as-received S0383-70, however the combined bake at $205{ }^{\circ} \mathrm{C}$ plus AO treatments did lower TML by $78 \%$ and CVCM by $69 \%$ for ELA-SA-401. Thus ELA-SA-401 may be advantageous in applications where very low outgassing is needed.

Figure 2 represents the effects of the $1.25 \times 10^{20}$ atoms $/ \mathrm{cm}^{2}$ AO fluence on outgassing of both the S0383-70 and ELA-SA-401 compounds. A slight decline in outgas is observed for the S0383-70 compound relative to as-received. ELA-SA401 did not show a significant change in outgas properties after the AO treatment.

Figure 2 shows a slight increase in outgassing for S0383-70, compared to asreceived, after the application of $1.2 \mathrm{mg} / \mathrm{cm}^{2}$ of Braycote Micronic $601 \mathrm{EF}$ perfluoroether grease. However the greased seal still achieves NASA's outgas requirements of TML $<1 \%$ and CVCM $<0.1 \%$. Based on the standard deviation of TML and CVCM measurements and expected detection limits, the uncertainty of TML and CVCM results is judged to be $+/-0.02 \%$ : this uncertainty is shown as error bars on Fig.2 [12].

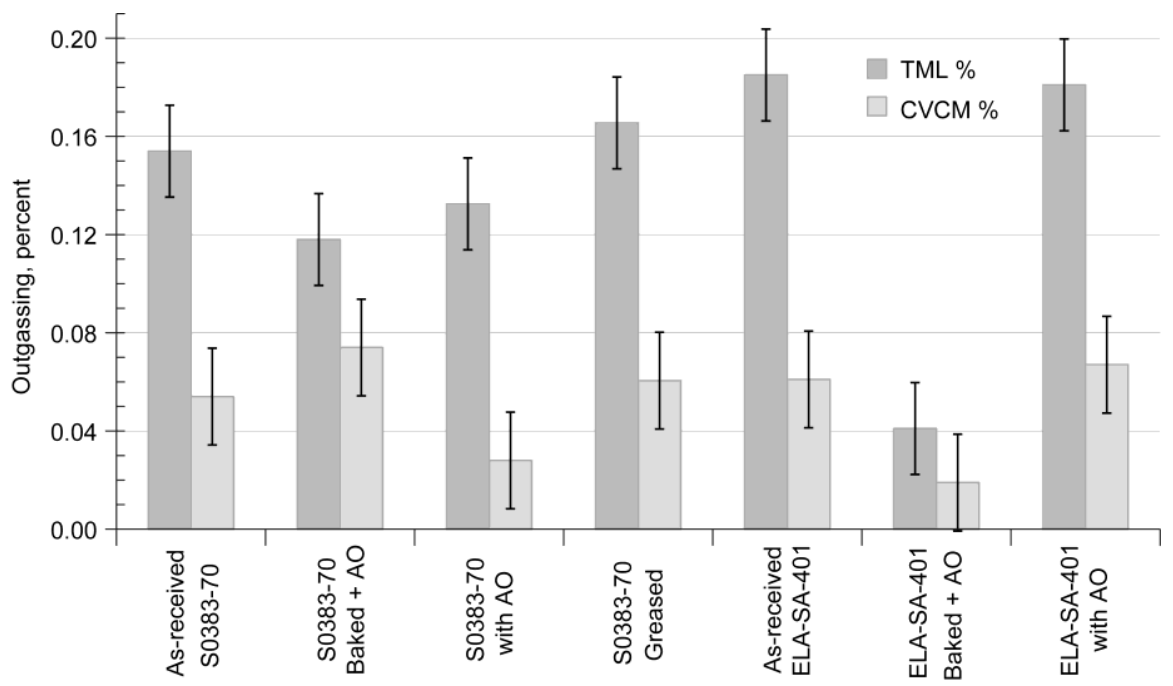

Fig.2 Effect of heat treatment + Atomic Oxygen (AO), Atomic Oxygen, and grease coating on the outgassing of S0383-70 and ELA-SA-401. 


\section{Conclusions}

A number of adhesion tests were conducted on silicone elastomer Parker S0383-70 material. Of the various adhesion reduction techniques evaluated, the AO pre-treatment of $1.25 \times 10^{20}$ atoms $/ \mathrm{cm}^{2}$ lowered adhesion the most. For seal-onseal $(\mathrm{SoS})$ operation modes the seals showed reduced unit adhesion from 26.8 psi to 0.2 psi and for seal-on-aluminum (SoAl) operation modes unit adhesion went from 6.04 psi to 0.18 psi. Application of a thin coat of Braycote 601EF perfluoroether grease also reduced adhesion, but to a lesser degree; for SoS the unit adhesion went from 26.8 psi to 8.75 psi and for SoAl the unit adhesion went from 6.04 psi to 1.53 psi. For specimens that were first pre-treated with AO and further applied with a thin coat of Braycote Micronic 601EF perfluoroether grease the reduction in unit adhesion for SoS went from 26.8 psi to 2.74 psi and SoAl went from 6.0 psi to 1.10 psi. The AO pre-treatment enables S0383-70 to achieve the low adhesion levels we expect to need for docking seal applications $(<2 \mathrm{psi})$.

Outgassing in ELA-SA-401 was not changed after AO pre-treatment of $1.25 \times 10^{20}$ atoms $/ \mathrm{cm}^{2}$. However, after the bake plus AO pre-treatment the TML and CVCM of ELA-SA-401 decreased by $78 \%$ and $69 \%$, respectively. Outgassing in S0383-70 slightly decreased after AO pre-treatment and did not significantly change after the bake plus AO treatment. Outgassing was higher for Braycote 601EF perfluoroether grease-coated S0383-70 compared to as-received S0383-70, however the outgassing with applied grease was still below NASA's TML and CVCM percentage requirements of TML $<1 \%$ and $\mathrm{CVCM}<0.1 \%$.

\section{Acknowledgments}

The authors wish to thank Bruce Banks and Sharon Miller for their assistance with AO exposures, Mark Jaster for his help with heat treatments, and William Anderer for mechanical support.

\section{References}

[1] "Overview of LIDS Docking Seals Development" Pat Dunlap, B. Steinetz, and C. Daniels, 2008 NASA Seal/Secondary Air System Research Symp., NASA/CP-2009-215677.

[2] Lewis, J.L., Carroll, M.B., Morales, R.H., and Le, T.D., National Aeronautics and Space Administration (U.S. Government), Washington, D.C., "Androgynous, Reconfigurable Closed Loop Feedback Controlled Low Impact Docking System with Load Sensing Electromagnetic Capture Ring," U.S. Patent No. 6,354,540, March 12, 2002.

[3] "Apollo Seals: A Basis for the Crew Exploration Vehicle Seals" J.R. Finkbeiner, P.H. Dunlap Jr., B.M. Steinetz, C.C. Daniels, AIAA-2006-5259, presented at the $42^{\text {nd }}$ AIAA/ASME/SAE/ASEE Joint Propulsion Conf. Sacramento CA, 2006; also available as NASA/TM-2006-214372.

[4] "Adhesion of Silicone Elastomer Seals for NASA's Crew Exploration Vehicle" H.C. de Groh III, S.K.R. Miller, I.M. Smith, C.C. Daniels, and B.M. Steinetz, 44th AIAA/ASME/SAE/ASEE, Joint Propulsion Conference, July 2008, Pa- 
per No. AIAA-2008-4625, July 21, 2008 Hartford, CT; also printed as NASA/TM-2008-215433.

[5] "An Experimental Investigation of Silicone-to-Metal Bond Strength in Composite Space Docking System Seals" M.C. Conrad, C.C. Daniels, and M.B. Bastrzyk, NASA/CR-2010-216886, Oct. 2010.

[6] "Space Environment Effects on Silicone Seal Materials," H.C. de Groh III, Christopher C. Daniels, J.A. Dever, S.K. Miller, D.L. Waters, J.R. Finkbeiner, P.H. Dunlap Jr., and B.M. Steinetz, April 2010, NASA/TM-2010-216332.

[7] "Atomic Oxygen Interactions with FEP Teflon and Silicones on LDEF" B.A. Banks, J.A. Dever, L. Gebauer, C.M. Hill, LDEF-69 Months in Space, page 801, Proceedings, NASA First Post-Retrieval Symp., 1991.

[8] "Performance and Analysis of Perfluorinated Grease Used on Space Shuttle Actuators," W. Morales, K.W. Street Jr., and E.V. Zaretsky, April 2009, NASA/TM-2009-215605.

[9] "Process Specification for the Application of Liquid Lubricants," Jay E. Bennett, Engineering Directorate, Structural Engineering Div., NASA JSC, Jan. 2007, PRC-8002C.

[10] "Product Data, Castrol Braycote Micronic 601 EF," Castrol Industrial North America Inc., Naperville IL.

[11] ASTM Designation: E 595-93 (Reapproved 2003) ASTM International, 100 Barr Harbor Dr. PO Box C700, W. Conshohocken, PA 19428-2959, USA.

[12] Test Report for: Mass Loss and Collected Volatile Condensable Materials, NuSil Silicone Technology LLC, Carpinteria CA, 2006. 